\author{
V International Forum on Teacher Education
}

\title{
Peculiarities of Educators' Emotional Burnout in Preschool Educational Institutions Depending on the Length of Professional Experience
}

\author{
Tatyana P. Sharay* \\ Kazan Federal University, 420008, Kazan (Russia), 18 Kremlyovskaya street
}

\begin{abstract}
The relevance of the issue is based on the transition of Russian pre-school educational system to new Federal State Educational Standards of Preschool Education. The standards are based on the ideas of humanization and socialization of educational process, implementation of the principles of individual-oriented upbringing and education of children. It places demands on the educator's personal resources and it often results in emotional overloads and difficulties in educators' psychological state and can lead to emotional burnout. The aim of this paper is to identify individual psychological peculiarities of educators that cause emotional burnout. The leading research method is psychological testing of educators in preschool educational institutions followed by mathematical processing of results. The article presents the results of investigation of the connection of emotional burnout with parameters of self-attitude, length of work experience and age. On the basis of the results there have been given recommendations on developing the programs of psychological prevention of emotional burnout in preschool educational institutions depending on the length of work experience.
\end{abstract}

Keywords: emotional burnout; self-attitude; parameters of self-attitude; preschool educators; individual psychological peculiarities of preschool educator; length of professional experience.

(C) 2019 Tatyana P. Sharay

This is an open access article distributed under the terms of the Creative Commons Attribution License (CC BY 4.0), which permits unrestricted use, distribution, and reproduction in any medium, provided the original author and source are credited.

Published by Kazan Federal University and peer-reviewed under responsibility of IFTE-2019 (V International Forum on Teacher Education) 


\section{Introduction}

In the last decade the Russian preschool educational system imposes high demands on educators' personal resources as a result of introducing Federal State Educational Standards.

By the nature of their work preschool educators are the first candidates of emotional burnout. It is supported by regular communication with a large number of children (there are 25-35 people in the group), the responsibility for their life, the necessity to resolve conflict situations between children and with their parents, etc. The requirements for educators and their responsibilities increase with the transition to new state educational standards. Daily teaching practice shows the facts such as the loss of interest in pupils as individuals, inability of pupils to be their true self, simplification of the emotional content of professional communication. Many educators experience anxiety, sadness, depression, apathy, disappointment, chronic fatigue that destabilize their professional activity (Barabanova, 1995; Bolotnikova \& Poroh, 2016).

This fact explains the importance of understanding of the educators' personal peculiarities and resources that contribute or prevent educators' emotional burnout in preschool educational institutions.

\section{Purpose and objectives of the study}

The aim of this paper is to identify individual psychological peculiarities of educators that cause emotional burnout.

\section{Literature review}

Among the factors that prevent educators' emotional burnout researchers emphasize such personal peculiarities as a high level of self-actualization, a meaningful life and person's internality (Pervitskaya, 2013), a high level of empathy, reflexivity, extroversion, and a democratic communication style (Efremov, 2007).

Many researchers consider so-called self-processes as the main factors that influence emotional burnout (Dolgikh \& Veremchuk, 2017; Kolyshko, 2004; Orlova, 2013; Vodopianova \& Starchenkova, 2008).

Dolgikh and Veremchuk (2017) established that educators majoring in the humanities have such parameters of self-attitude as a high level of internal honesty, self-esteem, and inherent worth.

Self-attitude, in turn, is one of the person's key components. When we influence on self-attitude, we provide effective correction and prevention of emotional burnout (Vodopianova \& Starchenkova, 2008; Stolin, 2003).

According to the last statement, it is important to identify the peculiarities of self-attitude and its connection with educators' emotional burnout in preschool educational institutions.

\section{Methodology}

In the process of study we used the following methods: theoretical (analysis, synthesis, concretizing, summarizing); diagnostic (tests); ascertaining experiment; methods of mathematical statistics.

The study was conducted in three stages at the Kazan (Volga region) Federal University.

The first stage involved the theoretical analysis of methodological approaches, psychological and pedagogical literature, and dissertations on the studied topic. The research problem, aim, methods and plan of experimental study were specified.

At the second stage we applied a diagnostic test. We used Boyko's techniques of diagnosing the level of emotional burnout, Stolin and Pantileev's method of self-attitude, and mathematical tools 
(correlation analysis and student's t-test). There were 50 educators of different age and with a various length of professional experience. Participants were divided in two groups according to the length of professional experience. The first group included educators who had the length of professional experience less than 10 years -29 people (the average value is 5.6 years). In the second group there were educators who had the length of professional experience more than 10 years - 21 people (the average value is 19.5 years).

At the third stage the research findings were analyzed. On the basis of the results there have been given recommendations for developing the programs of psychological prevention of emotional burnout in preschool educational institutions depending on the length of professional experience.

\section{Results}

\section{The first stage}

The researchers has identified that there are few studies examining the connection of self-attitude with educators' emotional burnout in preschool educational institutions. Also, there is a lack of studies that deal with the peculiarities of self-attitude parameters in relation to the length of professional experience. This fact has determined the research problem.

The second stage

At the second stage we used the ascertaining experiment (diagnostic testing). The part-time students of the Institute of Psychology and Education of Kazan (Volga Region) Federal University acted as respondents. All of them were kindergarten teachers with the various length of professional experience (from 1 year to 35). The obtained results were processed using mathematical statistics methods such as correlation analysis and student's t-test. During processing the participants were divided in two groups. Teachers with the length of professional experience less than 10 years (the average value is 5.6 years) formed the first group. Educators with the length of professional experience more than 10 years (the average value is 19.5 years) comprised the second group.

At first, we made the comparative analysis of the average values of measured factors. The results are shown in Fig. 1 and Fig. 2. 


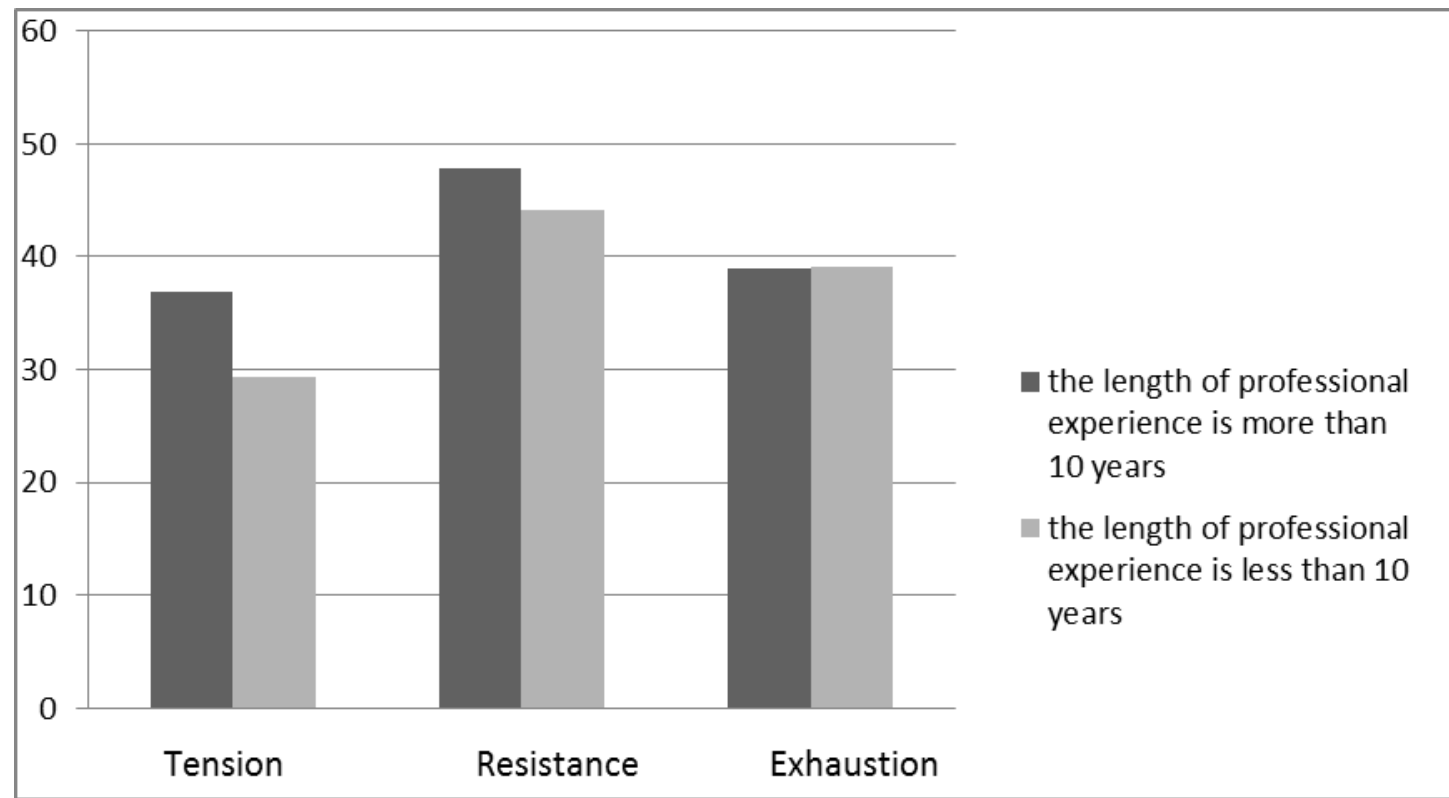

Fig. 1. The differences in the average values of emotional burnout phases in teachers with various length of professional experience (technique by Boiko)

The histogram (Fig.1) shows the average values of emotional burnout phases among the participants with the professional experience more or less than 10 years. These data indicate that three phases are present in educators with the professional experience more than 10 years. Tension is the first phase of emotional burnout. It is a signal and starting mechanism in the development of burnout. The second phase is resistance. At this stage a person resists the stress and seeks psychological comfort. The person tries to reduce the influence of external circumstances, forming certain psychological defenses. The third phase - exhaustion - is characterized by reducing of the energy level and weakening of nervous system. "Burnout" becomes an integral characteristic of the person.

The teachers who have been working for less than 10 years experience resistance and they start feeling exhaustion.

If we consider the average values of symptoms on each phase, we can notice that teachers with the length of professional experience more than 10 years have two symptoms. These are experience of traumatic circumstances (T1) and reduction of professional duties (R4) and 6 forming symptoms (T1, T4, R1, R3, E1 and E3). Educators with the length of professional experience less than 10 years do not have formed symptoms, but they have 6 forming symptoms (T1, R1, R3, R4, E3 and E4).

The results show that the more is the length of professional experience, the higher is level of emotional burnout in educators of preschool educational institutions. This statement is also confirmed by other studies. It is indicative that educators with the length of professional experience more than 10 years have such symptoms as experience of traumatic circumstances (T1) and reduction (simplification) of professional duties (R4). T1 factor means the experience of traumatic circumstances and expresses as awareness of traumatic factors of professional activities that are difficult to remove. Frustration and indignation are accumulating. Such insoluble situations lead to other burnout aspects. R4 factor (reduction of professional duties) is reflected in the attempt to facilitate or reduce the duties that require emotional 
costs. The workers do not receive basic attention.

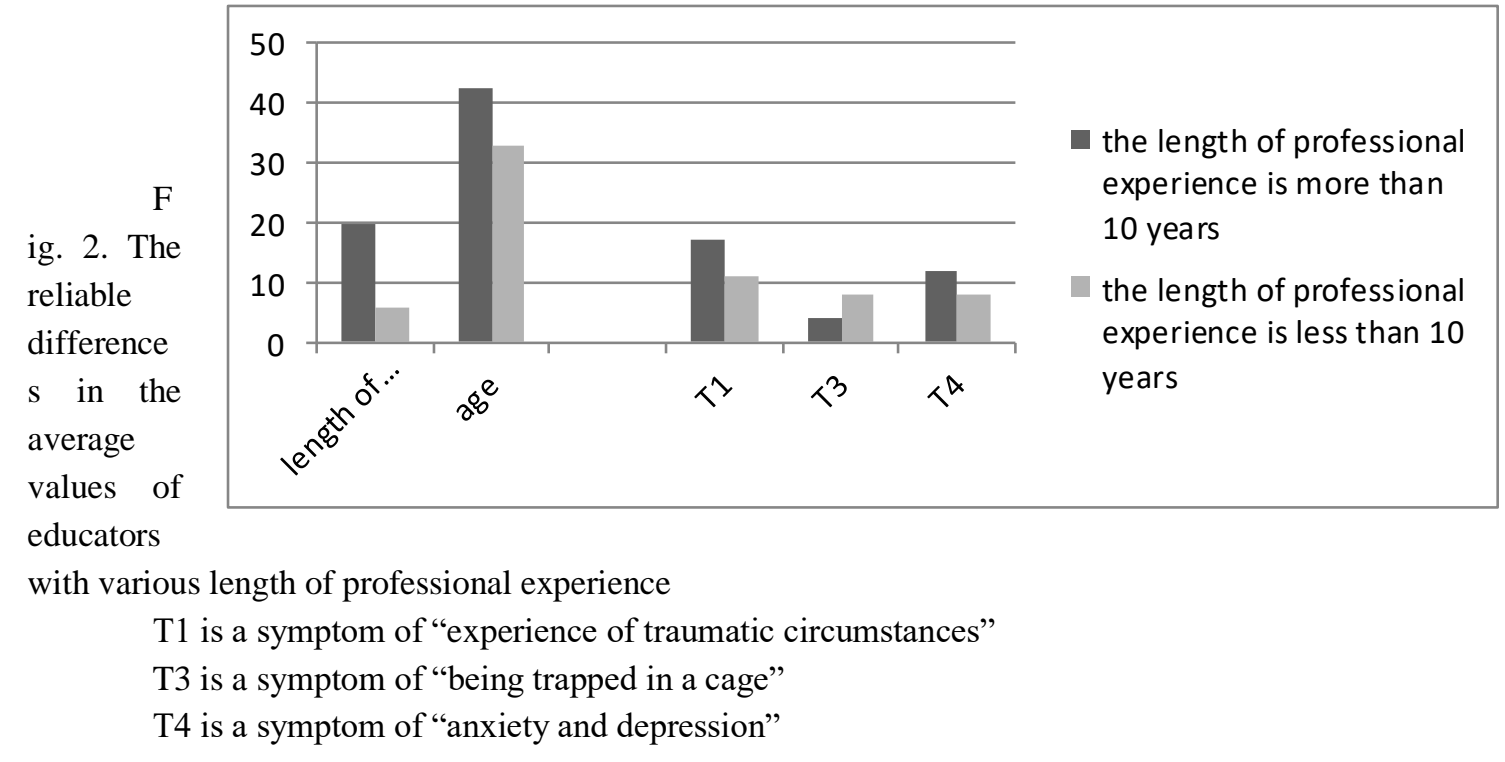
(Fig.2):

There have been found the differences in three symptoms of the emotional phase -tension phase

The T1 symptom (experience of traumatic circumstances) is higher among teachers with professional experience more than 10 years. As it can be seen in Fig. 2, their result is 17. It shows that this symptom has already been developed. The participants with the length of professional experience less than 10 years have the value that is equal to 11 . Thus, the symptom is in the process of its development.

The T3 symptom (being trapped in a cage) is higher among educators with professional experience less than 10 years. The value for their group is 8 . The value for experienced educators equals 4 . It shows that they do not experience this symptom, but it is likely to be developed among young educators.

The T4 symptom (anxiety and depression) is higher among educators who have been working more than 10 years. Experienced educators have the value that is equal to 12 (the symptom is being developed). In case of young educators their value is 8 (the symptom has not been developed).

These results are in line with the earlier conclusion that educators with the length of professional experience more than 10 years have a higher level of emotional burnout than those who have been working less than 10 years. Furthermore, the "being trapped in a cage" indicator (T3) that shows the feeling of helplessness (when a person cannot change the traumatic circumstances and suffers from intellectual and emotional stupor) is higher among the participants with the length of work experience less than 10 years. Although the T3 factor is not being formed, the tendency is seen.

Correlation analysis shows the relationship between emotional burnout parameters and selfattitude in both groups (Fig. 3 and Fig. 4). 


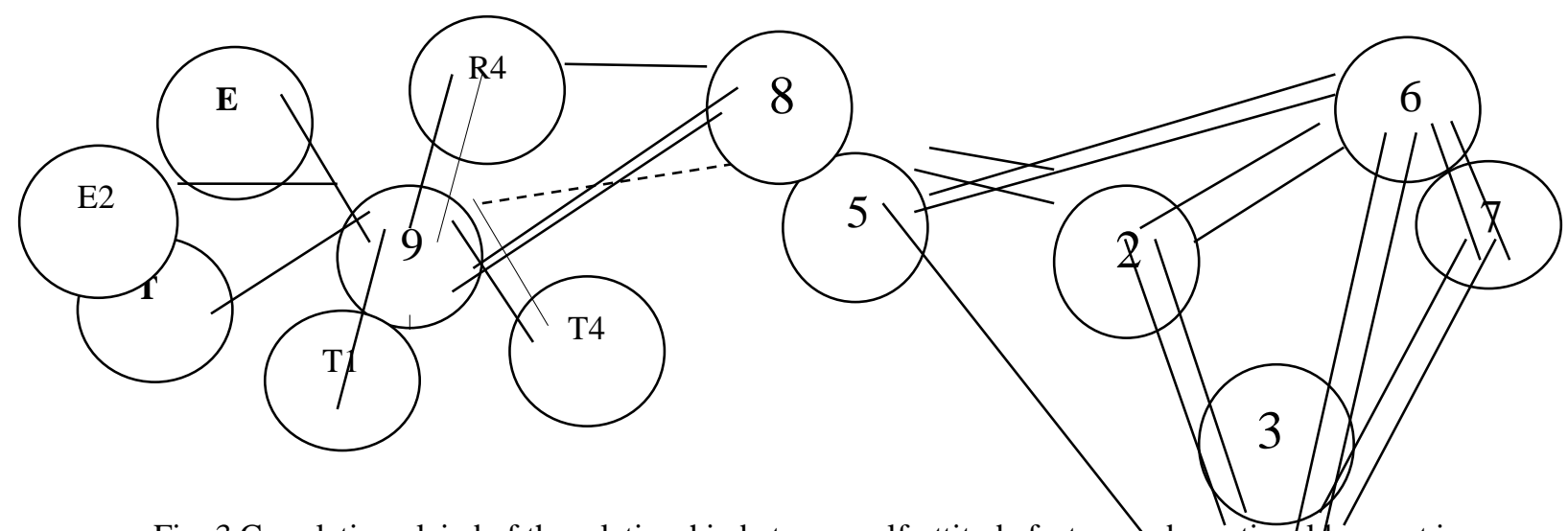

Fig. 3 Correlation pleiad of the relationship between self-attitude factors and emotional burnout in educators with the length of professional experience less than 10 yegrs

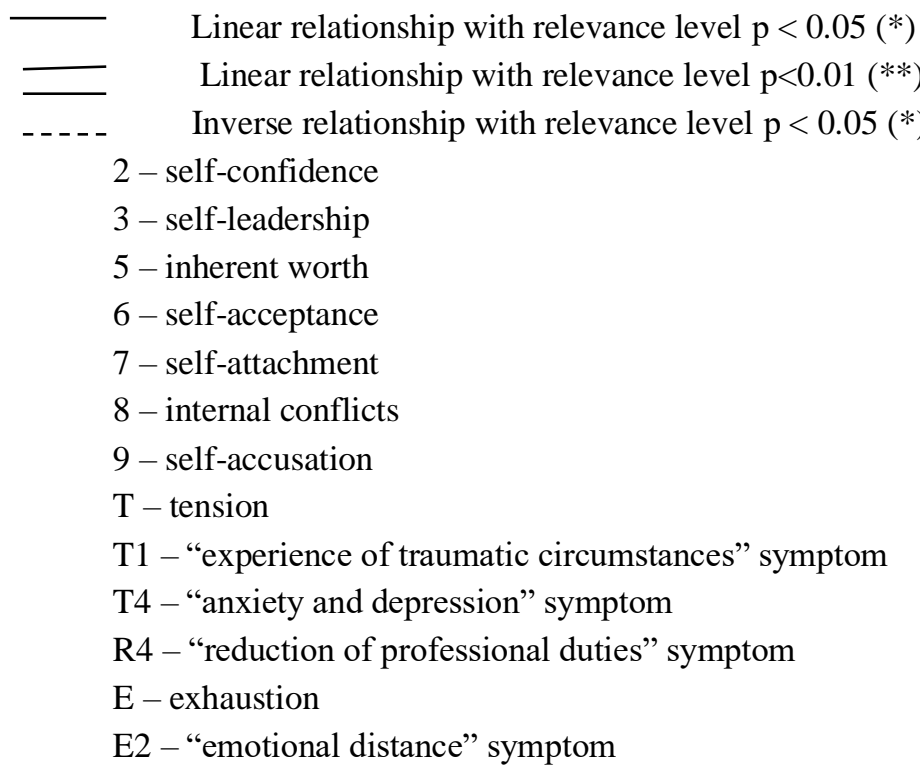

Fig. 3 shows the relationship between emotional burnout parameters and self-attitude of educators with the length of professional experience less than 10 years. The results demonstrate that self-accusation is a system-creating factor (it has the largest number of connections). Thus, the higher are self-accusation indicators, the higher are emotional burnout indicators such as "Tension", "Exhaustion" and their corresponding symptoms (see Fig. 3). On the other hand, self-accusation has an inverse relationship with an inherent worth factor (Factor 5). The higher are inherent worth indicators, the less are self-accusation indicators and vice versa. In the structure of self-attitude of educators with little professional experience we can notice self-acceptance and self-leadership factors as the system-creating factors. These factors have the largest number of linear connections with the self-attitude factors such as inherent worth, self-attachment, and self-esteem and with each other. The structure of self-attitude is sustainable and coherent in this group as a whole. It can be assumed that a tendency to self-accusation contributes to emotion burnout of the educators with the length of professional experience less than 10 years. The self-accusation, in turn, is connected with the low level of inherent worth. 

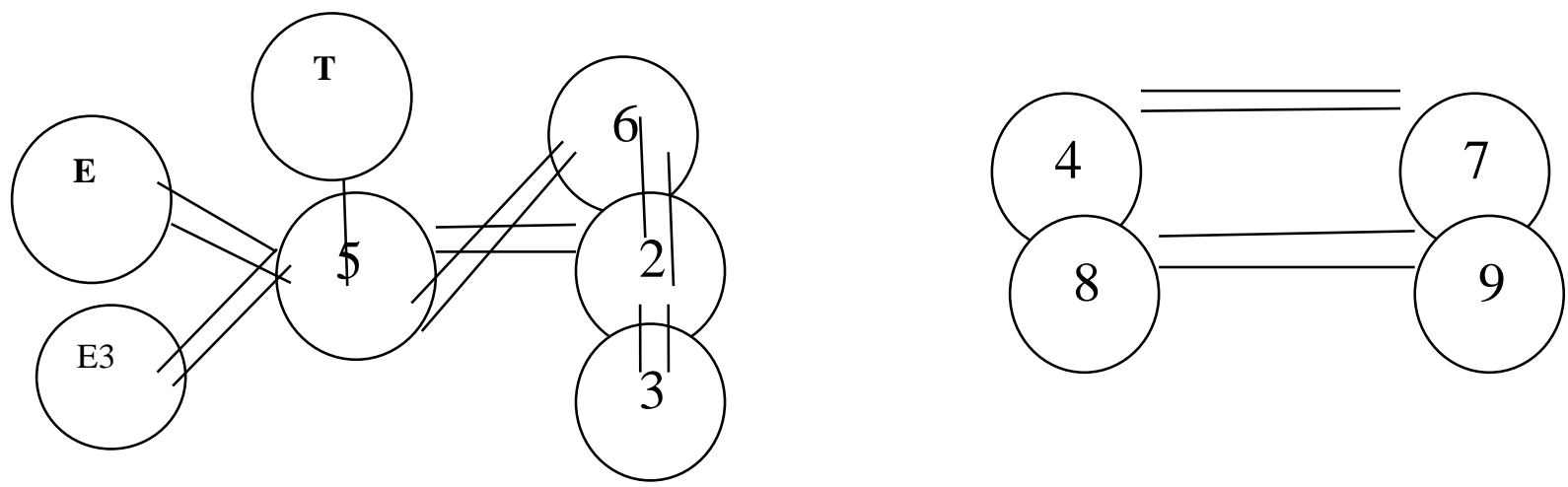

Fig. 4 Correlation pleiad of the relationship between self-attitude factors and emotional burnout in educators with the length of professional experience more than 10 years

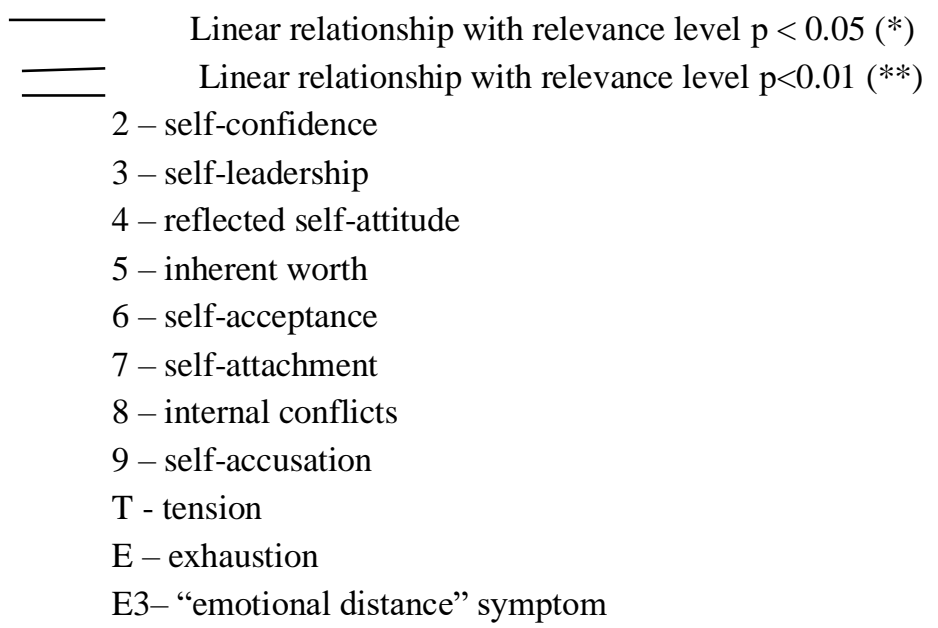

We can see a completely different situation with educators whose professional experience is more than 10 years (Fig. 4).

As it can be seen in the Fig. 4 the inherent worth is the system-creating factor. The inherent worth factor has linear connections with the emotional burnout factors such as "tension", "exhaustion" and the symptom of "emotional distance". Also, the inherent worth factor has linear connections with the selfconfidence and self-acceptance factors. It turns out that the more educators are tense, exhausted and emotionally distant, the more they feel their worth. And on the contrary, the high inherent worth is determined by the level of emotional burnout. The structure of self-attitude is not characterized by integrity and sustainability as can be seen in Fig. 4. We have such a defense mechanism when emotional burnout becomes a positive factor. This factor determines the person's worth.

The third stage

The obtained results show that the peculiarities of educators' emotional burnout in preschool educational institutions depend on the length of professional experience. This is important to consider when developing programs of psychological prevention and correction.

After 10 years of professional experience the phases of emotional burnout are in the stage of

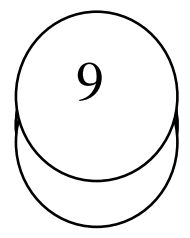


formation and there are no prevailing symptoms. It is important to focus on increasing the level of selfacceptance and self-leadership in the psychological work. It will contribute to more positive self-attitude and increasing the inherent worth, in particular. The high level of inherent worth contributes to reduction of self-accusation and as a result it leads to a decrease in the level of emotional burnout. The program of psychological prevention and correction of emotional burnout in educators with the length of professional experience less than 10 years that will take into account the given recommendations will be the most effective.

If we consider experienced teachers, we can see some prevailing symptoms ("experience of traumatic circumstances" and "anxiety and depression"). In fact, we deal with personal deformation of educators. It is important to begin the correction of emotional burnout in the process of working with identified psychological defenses. And we can talk about professional and long-term therapy.

\section{Discussions}

The study of psychological and pedagogical literature allows stating the lack of special studies devoted to the relationship between emotional burnout and self-attitude parameters in relation to educators in preschool educational institutions depending on the length of professional experience. Although, there are studies on the relationship between emotional burnout and self-processes: Vodopianova (2008), Galetskaia and Melnik (2007). For effective prevention and correction of emotional burnout, it is important to have studies that help to reveal specific mechanisms critical for emotional burnout.

\section{Conclusion}

It has been found out that emotional burnout of kindergarten teachers is connected with selfattitude parameters (inherent worth and self-accusation) and it has its own specific characteristics depending on the length of professional experience. It is important to consider the obtained research results in the process of planning the programs of psychological prevention and correction of emotional burnout among educators in preschool educational institutions. In case of teachers who have been working less than 10 years it is important to focus on the process of increasing the self-acceptance and selfleadership levels. This will contribute to an increase in inherent worth and a decrease in self-accusation. The high level of these indicators is directly connected with teachers' emotional burnout.

In case of educators whose professional experience is more than 10 years, we deal with professional and maybe personal deformation. Thus, when we talk about correction of emotional burnout in this group of specialists, it is important to understand the necessity for serious psychotherapy. This therapy will be aimed at restoring of a healthy mechanism of self-attitude when inherent worth is considered as a positive state and is not determined by the high levels of tension and exhaustion.

\section{References}

Barabanova, M. V. (1995). Study of psychological content of emotional burnout. Moscow University Psychology Bulletin, 14(1), 54-67.

Bolotnikova, O. P., \& Poroh, A. S. (2016). The syndrome of educators' emotional burnout in preschool educational institutions. Scientific reflection, 1(1), 5-7.

Dolgikh, N. P., \& Veremchuk, K. I. (2017). The influence of the educator's personality on relationship between preschool children. Meaning, functions and significance of different branches of practical psychology in the modern society. In E. N. Tkach (Eds.), Collection of scientific works (428-436). 
Efremov, K. (2007). Emotional burnout and how to deal with it. Social Pedagogy, 2, 97-102.

Kolyshko, A. M. (2004). Self-attitude psychology. Grodno: Grodno State University.

Kot, E. A. (2015). Professional self-attitude as a factor of educators' emotional burnout at the time of midlife crisis. Proceedings of VII International Research-to-Practice Conference: Systemogenesis of Educational and Professional Activities (pp. 194-196).

Orlova, E. A. (2013). Emotional and personal characteristics of school teachers as resources to overcome professional burnout syndrome. In Collection of Conferences NITS Sotsiosfera (pp. 52-58).

Pervitskaya, A. M. (2013). Study of emotional burnout of educators with different length of professional experience. Science and Modernity, 25(1), 190-193.

Stolin, V. V. (2003). Self-consciousness psychology. Samara: Bahrah-M.

Vodopianova, N. E., \& Starchenkova, E. S. (2008). Burnout syndrome: Diagnosis and prevention. St. Petersburg: Piter. 